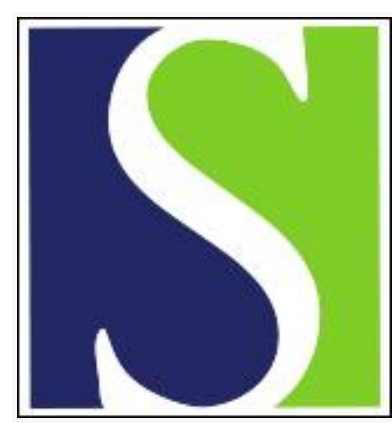

Scand J Work Environ Health 1995;21(2):143-149

https://doi.org/10.5271/sjweh.1369

Issue date: Apr 1995

Neurobehavioral effects of manganese in workers from a ferroalloy plant after temporary cessation of exposure.

by Lucchini R, Selis L, Folli D, Apostoli P, Mutti A, Vanoni O, Iregren A, Alessio L

Affiliation: Institute of Occupational Health, University of Brescia, Italy.

This article in PubMed: www.ncbi.nlm.nih.gov/pubmed/7618060 


\title{
Neurobehavioral effects of manganese in workers from a ferroalloy plant after temporary cessation of exposure
}

\author{
by Roberto Lucchini, MD, ${ }^{1}$ Luisella Selis, MD, ${ }^{2}$ Davide Folli, MD, ${ }^{2}$ Pietro Apostoli, MD, ${ }^{1}$ \\ Antonio Mutti, MD, ${ }^{2}$ Oscar Vanoni, MD, ${ }^{1}$ Anders Iregren, PhD, ${ }^{3}$ Lorenzo Alessio, $M D^{1}$
}

\begin{abstract}
Lucchini A, Selis L, Folli D, Apostoli P, Mutti A, Vanoni O, Iregren A, Alessio L. Neurobehavioral effects of manganese in workers from a ferroalloy plant after temporary cessation of exposure. Scand $J$ Work Environ Health 1995;21:143-9.

Objectives The goal of this study was to assess long-term neurobehavioral effects associated with low airborne concentrations of manganese in a ferroalloy plant.

Methods During a period of forced cessation of work ( 1 to $42 \mathrm{~d}$ ) neurobehavioral performance on tests of simple reaction time, finger tapping, digit span, additions, symbol digit, and shapes comparison was evaluated for 58 workers exposed from 1 to 28 (mean 13, SD 7) years to manganese. Airborne manganese concentrations in total dust had been reduced in the last 10 years from $70-1590 \mu \mathrm{g} \cdot \mathrm{m}^{-3}$ (geometric means in different areas) to $27-270 \mu \mathrm{g} \cdot \mathrm{m}^{-3}$. For each worker, manganese concentrations in blood and urine were measured, and a cumulative exposure index was also calculated.

Results Blood manganese and urinary manganese ranged from 4 to $18 \mu \mathrm{g} \cdot \mathrm{l}^{-1}\left(0.07\right.$ to $\left.0.03 \mu \mathrm{mol} \cdot \mathrm{l}^{-1}\right)$ and from 0.7 to $7 \mu \mathrm{g} \cdot 1^{-1}\left(0.01\right.$ to $\left.0.13 \mu \mathrm{mol} \cdot 1^{-1}\right)$, respectively. Significant relationships were found between the blood manganese and urinary manganese levels and between these biological measures and the cumulative exposure index. Correlations were also found between the blood manganese level, the urinary manganese level, and the cumulative exposure index and the following tests: finger tapping, symbol digit, digit span, and additions. The correlation coefficients increased as the latency time after the cessation of exposure and work seniority increased.

Conclusions The results support the hypothesis that the neurobehavioral effects observed at exposure levels well below current occupational standards are related to manganese body burden, which is better reflected by the blood manganese level after the cessation of exposure.
\end{abstract}

Key terms central nervous system, neurotoxicity, occupational exposure.

Toxic effects of manganese (Mn) on the central nervous system have been well described by many authors in cases of exposure to high levels in mines $(1,2)$ and in intoxications occurring in a ferromanganese alloy factory, where an unrepaired ventilation control system caused exposure levels of more than $20000 \cdot \mu \mathrm{g} \cdot \mathrm{m}^{-3}(3)$.

However, clinical signs of manganese intoxication have been reported also at exposure levels below $5000 \cdot \mu \mathrm{g} \cdot \mathrm{m}^{-3}(4,5)$. In 1981 a group of experts of the World Health Organization (WHO) concluded that "signs of adverse effects on the CNS may occur at manganese concentrations in air ranging from 2000 to $5000 \mu \mathrm{g} / \mathrm{m}^{3}$ [p 99]" (6). However, on the basis of a wide variation in individual susceptibility, WHO suggests that the minimum effect level is probably below $1000 \cdot \mu \mathrm{g} \cdot \mathrm{m}^{-3}(6)$.
In 1979 the American Conference of Governmental Industrial Hygienists (ACGIH) proposed a threshold limit value for a time-weighted average (TLV-TWA) of $1000 \cdot \mu \mathrm{g} \cdot \mathrm{m}^{-3}$ for manganese fumes and in $1988 \mathrm{a}$ TLVTWA of $5000 \mu \mathrm{g} \cdot \mathrm{m}^{-3}$ for manganese in inhalable dust. Recently, a TLV-TWA of $200 \cdot \mu \mathrm{g} \cdot \mathrm{m}^{-3}$ was proposed for manganese in inhalable dust (7).

Therefore, in order to determine the lowest exposure level at which early effects on the central nervous system occur, neurobehavioral field studies have been carried out (8-12). In these studies, alterations of response speed, motor functions, and memory have been found at airborne manganese concentrations well below the ACGIH TLV-TWA of $5000 \cdot \mu \mathrm{g} \cdot \mathrm{m}^{-3}$ for total dust. Exposure levels vary from $1000-4000 \cdot \mu \mathrm{g} \cdot \mathrm{m}^{-3}$ in the

1 Institute of Occupational Health, University of Brescia, Italy.

2 Laboratory of Industrial Toxicology, University of Parma, Italy.

3 National Institute of Occupational Health, Solna, Sweden.

Reprint requests to: Dr R Lucchini, Cattedra di Medicina del Lavoro dell’Universita‘di Brescia P.le Spedali Civili 1, 25125 Brescia, Italy. 
German study by Siegl \& Bergert (8) to $150 \cdot \mu \mathrm{g} \cdot \mathrm{m}^{-3}$ in the Swedish study by Iregren (10). In a more recent Belgian study (11), where the exposure level was approximately $950 \cdot \mu \mathrm{g} \cdot \mathrm{m}^{-3}$, Roels and his colleagues also calculated a "permissible dose" below which no increase in effects on hand steadiness would result. Such a dose was estimated as a lifetime integrated exposure index to manganese of $3575 \cdot \mu \mathrm{g} \cdot \mathrm{m}^{-3} \cdot$ year $^{-1}$ (for total dust) or $730 \cdot \mu \mathrm{g} \cdot \mathrm{m}^{-3} \cdot$ year $^{-1}$ (for respirable dust). For a professional life of 40 years this permissible dose corresponds to approximately $90 \cdot \mu \mathrm{g} \cdot \mathrm{m}^{-3}$ for inhalable dust and to $18 \cdot \mu \mathrm{g} \cdot \mathrm{m}^{-3}$ for respirable dust.

Dose-effect and dose-response relationships between current and cumulative manganese indicators of exposure and neurofunctional effects have rarely been observed. This situation might partly be due to the lack of reliable biological indicators of manganese exposure. Still urinary manganese (U-Mn) levels seem to reflect mainly current exposure $(9,13)$, while blood manganese (B-Mn) concentrations could be related to manganese body burden $(9,14)$.

Interest in manganese hazards at low levels of exposure has increased in the last few years also because of possible environmental risks concerning the replacement of lead in gasoline with methylcyclopentadienyl-manganese-tricarbonyl (MMT) (15).

The objective of this study was to assess neurobehavioral functions in a group of manganese workers during a period of temporary cessation of exposure, therefore eliminating the influence of night shifts on behavioral functions and making the evaluation of eventual effects unrelated to recent exposure possible. In addition to response speed, motor function, and memory tests, more complex cognitive tests were examined. This study on early effects in the central nervous system was part of an environmental and biological monitoring program (16).

\section{Subjects and methods}

\section{Study population}

A group of 58 male workers from an Italian ferroalloy plant volunteered to participate in the study (only 2 of the total number of 60 workers contacted having refused to participate). On the basis of job duties and area of work in the plant, they were divided into the following three subgroups according to the degree of exposure: group A: high-exposure group, including 19 furnace workers; group B: medium-exposure group, including 19 workers occupied mainly with maintenance operations; group $\mathrm{C}$ : low-exposure group, including 20 clerks, foremen, or laboratory technicians. Group A alternated night and day shifts in the same workweek and were continuously occupied by furnace and casting duties.

The exposure to manganese in the plant had been reduced during the last 10 years through technical improvements of charging and exhausting systems. In the furnace area, airborne manganese concentrations in the total dust content decreased from $900-2600 \cdot \mu \mathrm{g} \cdot \mathrm{m}^{-3}$ (geometric mean $1590 \cdot \mu \mathrm{g} \cdot \mathrm{m}^{-3}$ ) to $120-650 \cdot \mu \mathrm{g} \cdot \mathrm{m}^{-3}$ (geometric mean $270 \cdot \mu \mathrm{g} \cdot \mathrm{m}^{-3}$ ); in the maintenance area, manganese decreased from $180-760 \cdot \mu \mathrm{g} \cdot \mathrm{m}^{-3}$ (geometric mean $319 \cdot \mu \mathrm{g} \cdot \mathrm{m}^{-3}$ ) to $72-620 \cdot \mu \mathrm{g} \cdot \mathrm{m}^{-3}$ (geometric mean $\left.124 \cdot \mu \mathrm{g} \cdot \mathrm{m}^{-3}\right)$; in the service areas from $30-150$. $\mu \mathrm{g} \cdot \mathrm{m}^{-3}$ (geometric mean $70 \cdot \mu \mathrm{g} \cdot \mathrm{m}^{-3}$ ) to $9-40 \mu \mathrm{g}$. $\mathrm{m}^{-3}$ (geometric mean $27 \cdot \mu \mathrm{g} \cdot \mathrm{m}^{-3}$ ).

Almost all of the manganese (around 95\%) is in the form of manganese oxides $\left(\mathrm{MnO}_{\mathrm{x}}\right)$ in the entire plant area, the respirable fraction of manganese particles being around $50-60 \%$ ).

Number of school years, smoking habits, alcohol consumption, and general health status were assessed by a questionnaire and an interview. The information ascertained that the subjects were neither currently nor previously exposed to lead, mercury, or organic solvents. The subjects were screened for any neurological and neuropsychiatric illness and should not have taken medications that might have influenced their performance on psychometric tests.

\section{Data collection}

The subjects were examined during a period of temporary lay-off from work. The latency time after the cessation of exposure ranged from 1 to $42 \mathrm{~d}$. Half of the workers $(N=29)$ were tested in the first $13 \mathrm{~d}$, and the others later. The survey was conducted in the plant medical facility as follows: blood and urine sampling, administration of questionnaire, performance of neurobehavioral tests.

\section{Air sampling}

Air sampling for the measurement of airborne manganese concentrations was performed approximately one month before the beginning of the lay-off period. The exposure levels to airborne manganese concentrations in total dust were determined by personal and stationary sampling. The analyses were performed by electrothermal atomic absorption spectrometry (VARIAN SPECTRAA 400 Zeeman).

A cumulative exposure index (CEI) was calculated for each subject, multiplying the average annual airborne manganese concentration in respirable dust characteristic of each job by the number of years in which this activity was performed. The index was expressed in micrograms of manganese per cubic meter of air times duration of exposure in years. 


\section{Biological analyses}

After a previous check of all the sampling materials for lack of metal contamination, a venous blood sample of $5 \mathrm{ml}$ and a spot urine sample were collected immediately before the testing procedure, kept at $4^{\circ} \mathrm{C}$ and analyzed immediately. B-Mn and U-Mn were determined by electrothermal atomic absorption spectrometry coupled with a Zeeman effect background correction system (VARIAN SPECTRAA 400).

\section{Neurobehavioral examinations}

The psychometric test battery comprised seven tasks from the computer-administered test battery SPES (Swedish Performance Evaluation System) (17). The following tests were administered during a session of approximately 45 min with the use of a portable PC Toshiba T3200. The overall examination, which was carried out by three well-trained investigators, took approximately $1 \mathrm{~h}$ per subject.

Simple reaction time is a 6-min sustained attention task measuring response speed to an easily discriminated but temporally uncertain visual signal. The task is to press a key on the keyboard as quickly as possible when a bright square is presented on the display. Performance level is evaluated as the mean latency of 80 stimuli, and the variability is calculated as the standard deviation of these latencies.

Finger tapping measures the maximum speed of repetitive finger movement. Performance is evaluated as the mean number of taps during three 10-s trails for each hand (dominant/nondominant).

Digit span is a traditional test of short-term memory capacity. A series of digits are presented on the screen, and the task is to reproduce the series on a keyboard. Memory capacity is estimated from the performance on a minimum of 12 series of digits.

Additions measures the speed of simple mental arithmetic operations. Three horizontally placed digits are presented on the screen, and the task is to add them as quickly as possible and to enter the sum on the key board. The mean response latency is calculated from 40 trials.
Symbol digit is a revised version of a traditional test of perceptual speed. In this coding task digits should be paired to symbols according to a key. Performance is evaluated as the mean latency for 54 pairings.

Shapes comparison is a complex reaction time test. Each stimulus is a geometric figure circumscribed by another. The task is to respond as quickly as possible only when the figures are the same shape. Performance is evaluated as the mean latency to 48 critical stimuli.

Vocabulary is a test of verbal understanding comprising 45 stimuli. In this test the task is to indicate, among five alternatives, the correct synonym for a key word. The performance measure is the number of correct choices.

\section{Statistical methods}

An analysis of variance was performed to compare the mean values between the three different subgroups. In the testing for dose-effect relationships, the entire population of 58 subjects was considered, and the Pearson's correlation coefficient was calculated. Variables with a skewed distribution were logarythmically transformed to approximate the normal distribution. Analyses of multiple regression were also performed to control the influence of age, alcohol consumption, and educational level on certain variables. The level of statistical significance applied was $\mathrm{P}=0.05$.

\section{Results}

\section{Population characteristics}

In table 1 the principal characteristics of the workers in the three groups are reported according to the degree of exposure. The populations were similar regarding age, number of school years, smoking habits, and alcohol consumption, while a difference was noted in the vocabulary test score, for which the workers with low exposure showed generally better verbal abilities. This difference in the verbal test was not attributable to manganese expo-

Table 1. Characteristics of the three subgroups with different degrees of exposure.

\begin{tabular}{|c|c|c|c|c|c|c|c|c|c|c|c|c|c|c|c|c|}
\hline \multirow[t]{2}{*}{ Group } & \multicolumn{3}{|c|}{$\begin{array}{c}\text { Age } \\
\text { (years) }\end{array}$} & \multicolumn{3}{|c|}{$\begin{array}{c}\text { Exposure } \\
\text { (years) }\end{array}$} & $\begin{array}{l}\text { Education } \\
\text { (years) }\end{array}$ & \multicolumn{3}{|c|}{$\begin{array}{l}\text { Vocabulary } \\
\text { score }\end{array}$} & \multicolumn{3}{|c|}{$\begin{array}{c}\text { Smoking habit } \\
\text { index }\end{array}$} & \multicolumn{3}{|c|}{$\begin{array}{l}\text { Alcohol consumption } \\
(\mathrm{g} / \text { day })\end{array}$} \\
\hline & Mean & SD & Range & Mean & SD & Range & Mean SD Range & Mean & SD & Range 1 & Mean & SD F & Range & Mean & SD & Range \\
\hline $\begin{array}{l}\text { Low exposure } \\
(\mathrm{N}=19)\end{array}$ & 39.4 & 8.1 & $20-53$ & 12.9 & 6.0 & $2-28$ & $7.01 .8 \quad 5-13$ & 47.0 & 12.0 & $21-68$ & 32.4 & 1.0 & $1-4$ & 26.2 & 27.4 & $0-120$ \\
\hline $\begin{array}{l}\text { Medium exposure } \\
(N=19)\end{array}$ & 38.11 & 10.1 & $25-52$ & 11.8 & 6.3 & $4-25$ & $6.0 \quad 1.6 \quad 3-8$ & 31.7 & 11.1 & $9-52$ & 2.1 & 1.4 & $1-4$ & 33.3 & 37.0 & $0-100$ \\
\hline $\begin{array}{l}\text { High exposure } \\
(\mathrm{N}=20)\end{array}$ & 41.3 & 6.97 & $22-52$ & 13.8 & 6.2 & $2-27$ & $6.11 .8 \quad 5-13$ & 35.7 & 13.9 & $15-70$ & 2.3 & 1.2 & $1-4$ & 33.3 & 26.3 & $0-100$ \\
\hline
\end{tabular}


Table 2. Parameters of internal and external exposure in the three subgroups with different degrees of exposure. $(B-M n=$ manganese in blood, $\mathrm{U}-\mathrm{Mn}=$ manganese in urine, $\mathrm{CEI}=$ cumulative exposure index)

\begin{tabular}{|c|c|c|c|c|c|c|c|c|c|}
\hline \multirow[t]{2}{*}{ Group } & \multicolumn{3}{|c|}{ B-Mn } & \multicolumn{3}{|c|}{ U-Mn } & \multicolumn{3}{|c|}{$\mathrm{CEI}$} \\
\hline & $\begin{array}{c}\text { Geometric } \\
\text { mean } \\
\left(\left.\mu \mathrm{g} \cdot\right|^{-1}\right)^{\mathrm{a}}\end{array}$ & $\begin{array}{c}\text { Geometric } \\
S D \\
\left(\mu g \cdot \cdot^{-1}\right)^{a}\end{array}$ & $\begin{array}{c}\text { Range } \\
(\mu g \cdot \mid-1)^{\mathrm{a}}\end{array}$ & $\begin{array}{c}\text { Geometric } \\
\text { mean } \\
\left(\mu g \cdot I^{-1}\right)^{a}\end{array}$ & $\begin{array}{c}\text { Geometric } \\
\text { SD } \\
\left(\left.\mu \mathrm{g} \cdot\right|^{-1}\right)^{\mathrm{a}}\end{array}$ & $\begin{array}{c}\text { Range } \\
\left(\mu \mathrm{g} \cdot \mathrm{L}^{-1}\right)^{\mathrm{a}}\end{array}$ & $\begin{array}{c}\text { Geometric } \\
\text { mean } \\
\left(\mu g \cdot m^{-3}\right. \\
\left.\text { year }{ }^{-1}\right)\end{array}$ & $\begin{array}{c}\text { Geometric } \\
\text { SD } \\
\left(\mu g \cdot \mathrm{m}^{-3} \text {. }\right. \\
\left.\text { year }{ }^{-1}\right)\end{array}$ & $\begin{array}{c}\text { Range } \\
\left(\mu \mathrm{g} \cdot \mathrm{m}^{-3}\right.\end{array}$ \\
\hline $\begin{array}{l}\text { Low exposure } \\
(\mathrm{N}=19)\end{array}$ & 6.0 & 0.7 & $4-7.4$ & 1.7 & 1.2 & $0.7-7$ & 176.7 & 213 & $1-943$ \\
\hline $\begin{array}{l}\text { Medium exposure } \\
(\mathbb{N}=19)\end{array}$ & 8.6 & 0.6 & $7.9-9.5$ & 2.3 & 1.3 & $0.7-6$ & 199.2 & 260 & $9-1023$ \\
\hline $\begin{array}{l}\text { High exposure } \\
(N=20)\end{array}$ & 11.9 & 1.8 & $9.6-18$ & 2.8 & 0.8 & $0.9-5$ & 668 & 590 & $15-2130$ \\
\hline $\begin{array}{l}\text { Level of } \\
\text { significance }\end{array}$ & $P$ & $<0.0001$ & & & $<0.05$ & & & $<0.0001$ & \\
\hline
\end{tabular}

a $1 \mu \mathrm{g} \cdot \mathrm{l}^{-1}=0.018 \mu \mathrm{mol} \cdot \mathrm{I}^{-1}$.

$\mathrm{y}=\log \mathrm{B}-\mathrm{Mn}$

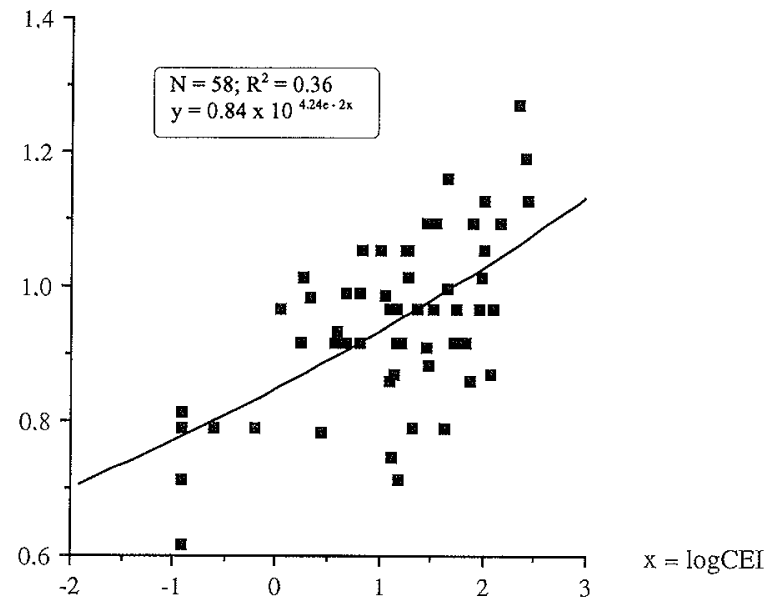

Figure 1. Correlation between $\log \mathrm{B}-\mathrm{Mn}$ and $\log \mathrm{CEI}$.

Table 3. Variations in the relationships between the indicators of internal and external exposure for the function of latency time after the cessation of exposure. (CEI = cumulative exposure index, $\mathrm{B}-\mathrm{Mn}=$ manganese in blood, $\mathrm{U}-\mathrm{Mn}=$ manganese in urine).

\begin{tabular}{|c|c|c|c|}
\hline Correlation & $N$ & $\mathrm{R}^{2}$ & $P$ \\
\hline \multicolumn{4}{|l|}{ CEI - B-Mn } \\
\hline $\begin{array}{l}\text { Entire group of workers } \\
\text { Workers tested }<13 \mathrm{~d} \text { after }\end{array}$ & 58 & 0.36 & 0.0001 \\
\hline & 29 & 0.31 & 0.002 \\
\hline exposure cessation & 29 & 0.41 & 0.0002 \\
\hline \multicolumn{4}{|l|}{ B-Mn - U-Mn } \\
\hline $\begin{array}{l}\text { Entire group of workers } \\
\text { Workers tested }<13 \mathrm{~d} \text { after }\end{array}$ & 58 & 0.23 & 0.0002 \\
\hline $\begin{array}{l}\text { exposure cessation } \\
\text { Workers tested }>13 \mathrm{~d} \text { after }\end{array}$ & 29 & 0.15 & 0.04 \\
\hline exposure cessation & 29 & 0.28 & 0.003 \\
\hline \multicolumn{4}{|l|}{ CEI - U-Mn } \\
\hline $\begin{array}{l}\text { Entire group of workers } \\
\text { Workers tested }<13 \mathrm{~d} \text { after }\end{array}$ & 58 & 0.16 & 0.002 \\
\hline $\begin{array}{l}\text { exposure cessation } \\
\text { Workers tested }>13 \mathrm{~d} \text { after }\end{array}$ & 29 & 0.00 & 0.8 \\
\hline exposure cessation & 29 & 0.15 & 0.03 \\
\hline
\end{tabular}

sure, but to higher technical skill. Since the groups were not exactly comparable in cognitive abilities, the difference in the vocabulary tests was controlled for in the statistical calculations by means of an analysis of covariance, with the vocabulary test results as the covariate.

\section{Exposure parameters}

Table 2 shows the average values for the B-Mn and U-Mn levels and the CEI in the three exposure groups with the results of the analysis of variance. All of the internal and external exposure parameters were statistically different in the three exposure groups.

After the transformation of the B-Mn and U-Mn level and the CEI in the logarithmic form, a good correlation was observed, on an individual basis, between $\log \mathrm{B}-\mathrm{Mn}$ and $\log C E I\left(r^{2}=0.36, P=0.0001\right)$ (figure 1), between $\log \mathrm{B}-\mathrm{Mn}$ and $\log \mathrm{U}-\mathrm{Mn}\left(\mathrm{r}^{2}=0.23, \mathrm{P}=0.0002\right)$, and between $\log \mathrm{U}-\mathrm{Mn}$ and $\log \mathrm{CEI}\left(\mathrm{r}^{2}=0.16, \mathrm{P}=0.0017\right)$. In general the correlation coefficients $\left(\mathrm{r}^{2}\right)$ increased when only the subjects that had been tested more than $13 \mathrm{~d}$ after the cessation of exposure were considered (table 3 ).

The B-Mn and U-Mn concentrations were examined with regard to the latency time after the cessation of exposure, and they were found not to vary significantly.

\section{Neurobehavioral effects}

Performance data for the three groups of workers, as well as the significance levels for the differences between these groups, are shown in table 4 . The workers of the high-exposure group exhibited poorer performance, as compared with the workers of the medium- and lowexposure groups, on several tasks. The differences were significant for the tests of additions, symbol digit, finger tapping, and digit span. The difference in vocabulary abilities between the groups was controlled by means of an analysis of covariance, which revealed that most of the performance differences observed between the three groups were not related to verbal abilities. 
Table 4. Results of the neurobehavioral tests for the three subgroups with different degrees of exposure.

\begin{tabular}{|c|c|c|c|c|c|c|c|c|c|c|c|c|c|c|c|}
\hline \multirow[t]{2}{*}{ Group } & \multicolumn{3}{|c|}{ Simple reaction time } & \multicolumn{3}{|c|}{ Shapes comparison } & \multicolumn{2}{|c|}{ Additions } & \multicolumn{3}{|c|}{ Symbol digit } & \multicolumn{2}{|c|}{ Finger tapping } & \multicolumn{2}{|c|}{ Digit span } \\
\hline & Mean & $S D$ & Range & Mean & SD & Range & Mean SD & Range & & ean SD & Range & Mean & SD Range & Mean SD & Range \\
\hline$=191$ & 237.2 & 16.1 & $207-277$ & 623.3 & 53.1 & $500-729$ & 3.60 .82 & $2-5.9$ & 3.2 & 0.672 & -4.8 & 69.1 & 8.155 & 7.91 .1 & $5.5-9.5$ \\
\hline & 246.5 & 29.1 & $199-303$ & 619.2 & 61.0 & $495-720$ & 4.41 .02 & $.7-6.3$ & 3.6 & 60.9 & $2.4-6.6$ & 60.8 & $7.143-70$ & 6.51 .6 & $3.5-8.5$ \\
\hline$(N=20)$ & 241.5 & 23.9 & $194-316$ & 638.5 & 56.3 & $496-758$ & 5.00 .93 & $.0-7.3$ & 4.0 & 0.7 & $2.9-6.0$ & 64.7 & $5.548-75$ & 6.71 .2 & $4.5-9.5$ \\
\hline $\begin{array}{l}\text { evel of } \\
\text { ignificance }\end{array}$ & $\mathrm{P}$ & NS & & & NS & & $<0.00$ & & & $<0.05^{\mathrm{a}}$ & & & $<0.001^{\mathrm{a}}$ & $<0.000$ & $01^{\mathrm{a}}$ \\
\hline
\end{tabular}

a $95 \%$ significance of high exposure group versus low exposure group.

Regarding the analyses of dose-effect relationships, the effect measures were not related to the number of years employed in manganese-exposed work. Instead, a correlation was observed between the vocabulary test score and some of the tests (table 5). After the transformation in the logarithmic form of the data with a skewed distribution, significant correlations were found between $\log \mathrm{B}-\mathrm{Mn}$ and the tests of additions, log symbol digit, digit span, and log finger tapping; between $\log U-\mathrm{Mn}$ and additions; and between $\log C E I$ and $\log$ symbol digit. Almost all of these relationships (except logCEI-log symbol digit) were still significant after control for vocabulary score (table 6).

As shown in tables 7 and 8 , further analyses of doseeffect relationships also revealed different correlation degrees with regard to latency after the cessation of exposure and also to work seniority. However, no significant relationship was observed between the vocabulary score and the two parameters of latency after exposure and work seniority. Furthermore, no significant variation occurred in the correlations between the vocabulary test and the neurobehavioral tests with regard to latency after exposure and work seniority.

\section{Discussion}

The present investigation analyzed the results of a crosssectional study among a group of male workers with different degrees of exposure to manganese dust. The duration of exposure was less than 30 years for all of the workers (range $1-28$ years, average 13 years). In the last 10 years the average exposure levels in different work areas diminished from a range of $70-1590 \mu \mathrm{g}$. $\mathrm{m}^{-3}$ to a range of $27-270 \mu \mathrm{g} \cdot \mathrm{m}^{-3}$. Since no major changes in the production volume, the production process, or ventilation system had occurred before this time, it can be assumed that previous levels were approximately in the same range as those of 10 years ago.
Table 5. Intercorrelations between the results of the neurobehavioral tests and the vocabulary test score.

\begin{tabular}{lccc}
\hline Correlation & $\mathrm{N}$ & $\mathrm{R}^{2}$ & $\mathrm{P}$ \\
\hline Vocabulary - simple reaction time & 57 & 0.0 & $\mathrm{NS}$ \\
Vocabulary - shapes comparison & 56 & 0.1 & $\mathrm{NS}$ \\
Vocabulary - additions & 51 & 0.3 & 0.0001 \\
Vocabulary - symbol digit & 53 & 0.3 & 0.0001 \\
Vocabulary - finger tapping & 57 & 0.2 & $\mathrm{NS}$ \\
Vocabulary - digit span & 55 & 0.5 & 0.0001 \\
\hline
\end{tabular}

Table 6. Dose-effect relationship between B-Mn, U-Mn, and $\mathrm{CEI}$ and the neurobehavioral tests before and after controlling for the vocabulary test score. $(\mathrm{B}-\mathrm{Mn}=$ manganese in blood, $\mathrm{U}-\mathrm{Mn}=$ manganese in urine, $\mathrm{CEI}=$ cumulative exposure index, NS = not significant)

\begin{tabular}{lccccc}
\hline \multirow{2}{*}{ Correlation } & $N$ & \multicolumn{2}{c}{ Before } & \multicolumn{2}{c}{ After } \\
\cline { 3 - 6 } & & $R^{2}$ & $P$ & $R^{2}$ & $P$ \\
\hline B-Mn-symbol digit & 54 & 0.22 & 0.0004 & 0.20 & 0.004 \\
B-Mn - additions & 52 & 0.26 & 0.0001 & 0.22 & 0.001 \\
B-Mn - digit span & 56 & 0.12 & 0.01 & 0.12 & 0.05 \\
B-Mn - finger tapping & 54 & 0.15 & 0.004 & 0.12 & 0.05 \\
U-Mn - additions & 52 & 0.12 & 0.01 & 0.13 & 0.02 \\
CEI-symbol digit & 54 & 0.15 & 0.004 & 0.02 & NS \\
\hline
\end{tabular}

The finding of a significant correlation on an individual basis between external exposure, represented by CEI, and $\mathrm{B}-\mathrm{Mn}$ and $\mathrm{U}-\mathrm{Mn}$ is in contrast with the results from previous studies. In both of their studies, Roels and his colleagues $(9,11)$ found some correlation between U-Mn and current external exposure on a group basis only, and no correlation with B-Mn. Our hypothesis is that this difference between our results and those of previous studies may be due to the fact that the biological indicators of exposure were assessed after a period without exposure. This hypothesis is supported by the fact that the correlation coefficients between the biological and environmental indices of exposure increased with the time since the latest exposure. 
Table 7. Variations between the dose-effect relationships in the function of latency time after the cessation of exposure. ( $\mathrm{B}-\mathrm{Mn}=$ manganese in blood, $\mathrm{U}-\mathrm{Mn}=$ manganese in urine, $\mathrm{CEI}=$ cumulative exposure index, $\mathrm{NS}=$ not significant)

\begin{tabular}{|c|c|c|c|}
\hline Correlation & $N$ & $\mathrm{R}^{2}$ & $P$ \\
\hline \multicolumn{4}{|l|}{ B-Mn - symbol digit } \\
\hline $\begin{array}{l}\text { Entire group of workers } \\
\text { Workers tested }<13 \mathrm{~d} \text { after }\end{array}$ & 54 & 0.22 & 0.0004 \\
\hline $\begin{array}{l}\text { exposure cessation } \\
\text { Workers tested }>13 \mathrm{~d} \text { after }\end{array}$ & 27 & 0.20 & 0.02 \\
\hline exposure cessation & 27 & 0.27 & 0.006 \\
\hline \multicolumn{4}{|l|}{ B-Mn - additions } \\
\hline $\begin{array}{l}\text { Entire group of workers } \\
\text { Workers tested }<13 \mathrm{~d} \text { after }\end{array}$ & 52 & 0.26 & 0.0001 \\
\hline $\begin{array}{l}\text { exposure cessation } \\
\text { Workers tested }>13 \mathrm{~d} \text { after }\end{array}$ & 27 & 0.17 & 0.03 \\
\hline exposure cessation & 25 & 0.35 & 0.02 \\
\hline \multicolumn{4}{|l|}{ B-Mn - digit span } \\
\hline $\begin{array}{l}\text { Entire group of workers } \\
\text { Workers tested }<13 \mathrm{~d} \text { after }\end{array}$ & 56 & 0.12 & 0.01 \\
\hline $\begin{array}{l}\text { exposure cessation } \\
\text { Workers tested }>13 \mathrm{~d} \text { after }\end{array}$ & 29 & 0.06 & NS \\
\hline exposure cessation & 27 & 0.17 & 0.03 \\
\hline \multicolumn{4}{|l|}{ CEI - symbol digit } \\
\hline $\begin{array}{l}\text { Entire group of workers } \\
\text { Workers tested }<13 \mathrm{~d} \text { after }\end{array}$ & 54 & 0.15 & 0.004 \\
\hline $\begin{array}{l}\text { exposure cessation } \\
\text { Workers tested }>13 \mathrm{~d} \text { after }\end{array}$ & 27 & 0.04 & NS \\
\hline exposure cessation & 27 & 0.26 & 0.07 \\
\hline
\end{tabular}

Table 8. Variations between the dose-effect relationships in the function of work seniority. (B-Mn = mangasese in blood, $\mathrm{U}-\mathrm{M} \mathrm{n}$ = manganese in urine, $\mathrm{CEI}=$ cumulative exposure index, NS = not significant).

\begin{tabular}{llll}
\hline Correlation & $\mathrm{N}$ & $\mathrm{R}^{2}$ & $\mathrm{P}$ \\
\hline B-Mn - digit span & & & \\
$\quad$ Entire group of workers & 56 & 0.12 & 0.01 \\
$\quad$ Workers with < 13 years of exposure & 31 & 0.07 & $\mathrm{NS}$ \\
$\quad$ Workers with > 13 years of exposure & 25 & 0.20 & 0.024 \\
CEI - symbol digit & & & \\
$\quad$ Entire group of workers & 54 & 0.15 & 0.004 \\
$\quad$ Workers with < 13 years of exposure & 31 & 0.08 & $\mathrm{NS}$ \\
$\quad$ Workers with > 13 years of exposure & 23 & 0.22 & 0.02 \\
CEI - additions & & & \\
$\quad$ Entire group of workers & 52 & 0.04 & $\mathrm{NS}$ \\
$\quad$ Workers with < 13 years of exposure & 30 & 0.03 & $\mathrm{NS}$ \\
$\quad$ Workers with > 13 years of exposure & 22 & 0.29 & 0.009 \\
U-Mn - additions & & & \\
$\quad$ Entire group of workers & 52 & 0.12 & 0.01 \\
$\quad$ Workers with < 13 years of exposure & 30 & 0.02 & $\mathrm{NS}$ \\
$\quad$ Workers with > 13 years of exposure & 22 & 0.32 & 0.006 \\
\hline
\end{tabular}

In addition, a different "bioavailability" of manganese could partly explain the associations between the indicators of exposure found in this study. The half-time of manganese dioxide particulate (which is the chemical form of manganese in this plant) deposited in the lung alveoli is about two to three months (18), while it is shorter for more soluble manganese compounds, like manganese sulfate and manganese chloride, which were present in the first Belgian study on workers of a manganese salt producing plant (9).

B-Mn was better related to life-estimated manganese exposure and thus confirmed the observation that this indicator can better reflect manganese body burden $(9,14)$.

Impairment of performance was observed in motor function tests (finger tapping and symbol digit) and memory tests (digit span) and thus confirmed the findings of the studies by Roels et al $(9,11)$, Iregren $(10)$, and Mergler et al (12). In addition effects on more complex cognitive functions were noted, such as those revealed by the arithmetic task of the additions test and the coding task of the symbol digit test. The lack of effects on the response speed tests of simple reaction time and shapes comparison, a result in contrast with those of the studies by Siegl \& Bergert $(8)$, Roels et al $(9,11)$ and Iregren (10), may be related to the fact that these tests are generally more sensitive to "acute" or current exposure, therefore not being affected after its cessation. This discrepancy also appeared recently in the Montreal study of Mergler and her colleagues (12).

Dose-effect relationships were observed between the exposure parameters (B-Mn in particular) and additions, symbol digit, digit span and finger tapping. Also with these measures, the relationships improved with the latency time after the cessation of exposure and, to some degree, with work seniority.

The vocabulary score was lower for the most-exposed workers, a phenomenon frequently observed in neurobehavioral field studies. Nevertheless, the influence of intelligence, as measured by the vocabulary test, on performance, was fully eliminated by the covariance analysis. This analysis is likely to remove also some true effects of exposure, since part of these effects may be associated with the vocabulary score. In addition the improvement of the dose-effect relationships as a function of increased latency after exposure and of work seniority was clearly independent of any influence of the vocabulary test scores.

In conclusion, this study confirms the observation that exposure to manganese airborne concentrations well below the TLV of $5000 \mu \mathrm{g} \cdot \mathrm{m}^{-3}$ for less than 30 years is associated with slight impairments of central neural functions in clinically asymptomatic workers.

\section{Acknowledgments}

We are grateful to Professor Donna Mergler for her helpful suggestions. 


\section{References}

1. Couper $Y$. On the effect of black oxide of manganese when inhaled into the lungs. Br Ann Med Pharm Vital Stat Gen Sci 1837:1:41-2.

2. Shuler $P$, Oyanguren $H$, Maturana $V$, VaTenzuela A, Cruz E, Plaza V, et al. Manganese poisoning: environmental and medical study at a Chilean mine. Ind Med Surg 1957;26:167-73

3. Huang CC, Chu NS, Lu CS, Wang JD, Tsai JL, Tzeng JL, et al. Chronic manganese intoxication. Arch Neurol 1989;46:1104-6.

4. Tanaka S, Lieben J Manganese poisoning and exposure in Pennsylvania. Arch Environ Health 1969;19:674-84.

5. Chandra SV, Seth PK, Mankeshwar JK. Manganese poisoning: clinical and biochemical observations. Environ Res $1974 ; 7: 374-80$.

6. Organisation Mondiale de la Sante (OMS). Le manganèse Geneve: OMS, 1981. OMS Critères d'hygiène de l'environment; no 17

7. American Conference of Governmental Industrial Hygienists (ACGIH). ABBE-'93: threshold limit values for chemical substances and physical agents and biological exposure indices. Cincinnati, OH: ACGIH, 1992.

8. Siegl P, Bergert KD. Eine frühdiagnostische Überwachungsmethode bei Manganexposition. Z Gesante Hyg 1982;28: $524-6$.

9. Roels H, Lauwerys R, Buchet J-P, Genet P, Sarhan MJ, Hanotiau I, et al. Epidemiological survey among workers exposed to manganese: effects on lung, central nervous system, and some biological indexes. Am J Ind Med 1987;11:307-27.

10. Iregren A. Psychological test performance in foundry workers exposed to low levels of manganese. Neurotoxicol Teratol 1990;12:673-5.

11. Roels H, Ghyselen P, Buchet JP, Ceulemans E, Lawwerys R. Assessment of the permissible exposure level to manganese in workers exposed to manganese dioxide dust. $\mathrm{Br} \mathbf{J}$ Ind Med 1992;49:25-34.

12. Mergler D, Huel G, Bowler R, Iregren A, Belanger S, Baldwin $M$, et al. Nervous system dysfunction among workers with long-term exposure to manganese. Environ Res. 1994;64: $151-80$.

13. Smith LT, Ruhf RC, Whitman NE, Dugan T. Clinical manganism and exposure to manganese in the production and processing of ferromanganese alloy. J Occup Med 1973; 15:101-9.

14. Keen CL, Clegg MS, Lönnerdal B, Hurley LS. Whole-blood manganese as an indicator of body manganese. New Engl J Med 1983;308:1230.

15. United States Environmental Protection Agency. Health assessment document for manganese: final report. Cincinnati, OH: Environmental Criteria and Assessment Office, 1984. EPA-600/8-83-013F.

16. Apostoli P, Vanoni O, Alessio L. Four years follow up of manganese in a ferroalloy plant: proceedings of the 24th Congress of the International Commission on Occupational Health; 1993 Sep 26 - Oct 1. Nice: International Commission on Occupational Health, 1993:189.

17. Gamberale F, Iregren A, Kjellberg A. SPES: assessing the effects of the work environment on man with computerized performance testing. In: Karwowski W, Genaidy AM, Asfour SS, editors. Computer aided ergonomics: a researchers guide. London: Taylor \& Francis, 1990:381- 96.

18. Oberdoerster G, Cherian G. Manganese. In: Clarkson TW, Friberg L, Nordberg GF, Sager PR, editors. Biological monitoring of toxic metals. New York, NY: Plenum Press, 1988:283-301.

Received for publication: 12 November 1993 